\title{
Factors Associated with Loss to Follow-up during Treatment for Multidrug-Resistant Tuberculosis, the Philippines, 2012-2014
}

\author{
Thelma E. Tupasi, Anna Marie Celina G. Garfin, Ekaterina V. Kurbatova, Joan M. Mangan, \\ Ruth Orillaza-Chi, Leilani C. Naval, Glenn I. Balane, Ramon Basilio, Alexander Golubkov, \\ Evelyn S. Joson, Woo-jin Lew, Vivian Lofranco, Mariquita Mantala, Stuart Pancho, Jesus N. Sarol Jr.
}

To identify factors associated with loss to follow-up during treatment for multidrug-resistant (MDR) tuberculosis (TB) in the Philippines, we conducted a case-control study of adult patients who began receiving treatment for rifampin-resistant TB during July 1-December 31, 2012. Among 91 case-patients (those lost to follow-up) and 182 control-patients (those who adhered to treatment), independent factors associated with loss to follow-up included patients' higher self-rating of the severity of vomiting as an adverse drug reaction and alcohol abuse. Protective factors included receiving any type of assistance from the TB program, better TB knowledge, and higher levels of trust in and support from physicians and nurses. These results provide insights for designing interventions aimed at reducing patient loss to follow-up during treatment for MDR TB.

$\mathrm{T}$ he Philippines is 1 of 22 countries considered to have a high burden of tuberculosis (TB) (1), including multidrug-resistant (MDR) TB (resistant to isoniazid and rifampin) (1). Compared with treatment for drug-susceptible TB, treatment for MDR TB is longer, more expensive, and less effective, and it causes more medication side effects

Author affiliations: Tropical Disease Foundation, Inc., Makati City, the Philippines (T.E. Tupasi, L.C. Naval, G.I. Balane, E.S. Joson, J.N. Sarol Jr.); Department of Health, Manila, the Philippines (A.M.C.G. Garfin, R. Basilio); Centers for Disease Control and Prevention, Atlanta, Georgia, USA (E.V. Kurbatova, J.M. Mangan); Philippine Business for Social Progress-Innovations and Multisectoral Partnership to Achieve Control of Tuberculosis Project, Manila (R. Orillaza-Chi); US Agency for International Development (USAID), Washington, DC, USA (A. Golubkov); World Health Organization Philippines, Manila (W.-j. Lew);

The Lung Center of the Philippines, Manila (V. Lofranco,

S. Pancho); Technical Assistance to the Countries-USAID-funded activity, Manila (M. Mantala)

DOI: http://dx.doi.org/10.3201/eid2203.151788
(2-5). Resistance to anti-TB drugs has been detected in all regions of the Philippines; an estimated 8,500 MDR TB cases occurred in 2013 (6).

Programmatic Management of Drug-resistant Tuberculosis (PMDT) was jointly initiated in the Philippines in October 2000 by the private Makati Medical Center in Metro Manila and the Tropical Disease Foundation, Inc., in collaboration with the National TB Control Program and the local government unit, as the first directly observed therapy (DOTS)-plus pilot project for the management of MDR TB approved by the Green Light Committee (7). In 2003, a grant proposal from the Philippines for Round 2 of the Global Fund to Fight AIDS, Tuberculosis and Malaria included treatment for 500 patients with MDR TB (National Tuberculosis Control Program, the Philippines, 2013 Aug 25-Sep 6. Report of the Joint Program Review; 2013 Sep 30, unpub. data). This funding was approved and subsequently expanded to 2,500 MDR TB patients approved to receive treatment according to a Round 5 proposal. In 2010, a new coordination team for PMDT was established by the National TB Control Program/Department of Health; the Lung Center of the Philippines was the implementing arm for PMDT. As of September 2014, a total of 44 PMDT health facilities were located in 16 of 17 regions. The annual number of patients with drug-resistant TB who began receiving treatment under PMDT increased from 191 in the 2005 cohort to 2,056 in the 2012 cohort. Despite substantial progress made by PMDT in the Philippines, the proportion of patients for whom treatment was successful decreased from $73 \%$ in the 2005 cohort to $46 \%$ in the 2010 cohort, while the proportion of loss to follow-up increased from $13 \%$ to $38 \%$, respectively $(8)$. Even with recent efforts to improve retention of patients receiving treatment for TB (e.g., providing transportation allowance, financial incentives at treatment milestones, food baskets, and halfway houses for patients from remote areas), the proportion of patients lost to follow-up remains substantial. 
An effective approach to reducing loss to follow-up during treatment for MDR TB is needed (National Tuberculosis Control Program, the Philippines, 2013 Aug 25Sep 6. Report of the Joint Program Review; 2013 Sep 30, unpub. data), especially in light of data from a prospective multinational study demonstrating that among MDR TB patients lost to follow-up, almost a third had extensively drug-resistant or pre-extensively drug-resistant TB when treatment was started; drug resistance was acquired during treatment by an additional $12 \%(9,10)$. In addition, a third of those lost to follow-up remained culture-positive at last contact, enabling community transmission of strains with more extensive resistance (10). However, most studies of loss to follow-up were done retrospectively, through medical record reviews (11-17), and lacked a theoretical framework. Specific reasons why patients in the Philippines are lost to follow-up during MDR TB treatment are limited and based primarily on the views of healthcare providers. We aimed to determine which individual, diagnosis and treatment, interpersonal, healthcare setting, and social factors were significantly associated with patient loss to follow-up during MDR TB treatment in the Philippines.

\section{Methods}

\section{Study Design and Patient Population}

We conducted a case-control study among adult patients ( $\geq 18$ years of age) with confirmed MDR or rifampin-resistant TB for whom treatment was initiated during July 1-December 31, 2012, at PMDT treatment facilities in the Philippines. We excluded from study inmates, children $<18$ years of age, patients enrolled in pharmaceutical clinical trials, and patients who had a major psychiatric disorder or were physically incapacitated.

The study was approved by the institutional review board of the Tropical Disease Foundation, Inc., the Lung Center of the Philippines-Ethics Review Committee, and the Ethics Research Committee of the Philippine Tuberculosis Society, Inc. The US Centers for Disease Control and Prevention (CDC) determined that CDC staff involvement did not constitute engagement in human subject research and that submission for CDC institutional review board review was not required.

In the Philippines, the standardized treatment regimen for MDR TB is pyrazinamide, kanamycin, levofloxacin, prothionamide, and cycloserine; the intensive phase lasts $\geq 6$ months and the continuation phase an additional $\geq 12$ months. For this study, case-patients were defined as patients who were lost to follow-up from MDR TB treatment (i.e., patients whose treatment was interrupted for $\geq 2$ consecutive months) (18). Those who later returned (after being considered lost to follow-up) at the time of interview were eligible for inclusion in the study as case- patients. Control-patients were defined as patients who had continued treatment for MDR TB for $\geq 12$ months or who had a documented treatment outcome of cured, completed, or failed (18). Data collection and interviews were conducted from April 14 through July 31, 2014; thus, all control-patients were receiving MDR TB treatment for $\geq 15$ months.

Case-patients were identified by review of MDR TB registers. The number of patients who were lost to followup per treatment facility was assessed; centers with $\geq 3$ patients with drug-resistant TB who had been lost to follow-up by January 1, 2014, and who were not known to have died, were selected for logistical reasons. Field study staff attempted to find all eligible patients who were lost to follow-up and invite them to participate in the study. Two control-patients were randomly selected for each enrolled case-patient from the same PMDT treatment facilities at which treatment was initiated for case-patients. Of 986 eligible patients, a total of 273 were enrolled: 91 case-patients and 182 control-patients (Figure 1).

To characterize factors associated with loss to followup during MDR TB treatment, we followed a 5-level social ecologic model $(19,20)$ that focuses on individual and environmental factors that affect health outcomes: 1) individual factors; 2) interpersonal factors; 3 ) healthcare setting factors, such as individual experiences with services and relationships within the setting; 4) diagnosis and treatment factors; and 5) social factors (Figure 2). To operationalize each category of factors and develop data collection forms, investigators reviewed TB literature and a 2013 Joint Program Review of the National Tuberculosis Control Program in the Philippines, which was led by the World Health Organization (WHO), and solicited input from experts within the country.

\section{Data Collection}

Clinical and laboratory data were abstracted from participants' medical records by using standard data collection forms. In-depth interviews with a series of closed- and openended questions were conducted to collect information about the following: demographics, social history, adverse drug reaction experiences, TB knowledge, perceived barriers to treatment completion, self-efficacy to adhere to treatment (21), values and expectancies associated with treatment; psychosocial factors (e.g., stigma, sources of emotional support, and family dynamics), financial support, perceptions of the healthcare setting, their diagnosis, their prescribed treatment, impressions of and feedback for the PMDT program regarding the current TB enabler package and patient-centered activities, and interventions under consideration. Cumulative scores were calculated from items focused on 1) patient perceptions of disease severity and TB knowledge; 2) expected outcomes, treatment self-efficacy; 3) patient-reported social 
support from family and friends; 4) trust in, rapport with, and support from health center staff; and 5) stigma (Table 1). Case-patients were asked to report their primary reason for stopping treatment. (Interview and scoring instruments are available from T.E.T.)

\section{Data Analysis}

Data were entered in a Microsoft (Redmond, WA, USA) Access electronic database. Statistical analyses were performed by using SAS software version 9.3 (SAS Institute Inc., Cary, NC, USA). Thematic qualitative analysis was conducted by using Microsoft Excel software.

We assessed associations between individual, interpersonal, healthcare setting, diagnosis and treatment, and social factor data and an outcome of lost to follow-up. For continuous variables, we compared means (SDs) or medians (percentiles) or both, depending on the underlying distributions. The proportions of patients with characteristics of interest were compared between case-patients and control-patients by $\chi^{2}$ or Fisher exact tests, as appropriate. We calculated odds ratios with corresponding 95\% CIs. To identify independent factors associated with loss to followup, we performed multivariable logistic regression analyses. The initial multivariable model included covariates with epidemiologic, biological, or statistical associations with the dependent variable. We evaluated effect modification and confounding in the full model, and then we performed backward elimination to improve precision of the estimates (22). All tests were 2 -sided, and a p value of $\leq 0.05$ was considered statistically significant.

\section{Results}

Mean \pm SD age of the 273 study participants at start of MDR TB treatment was $39 \pm 13$ (median 40, range 16-68)

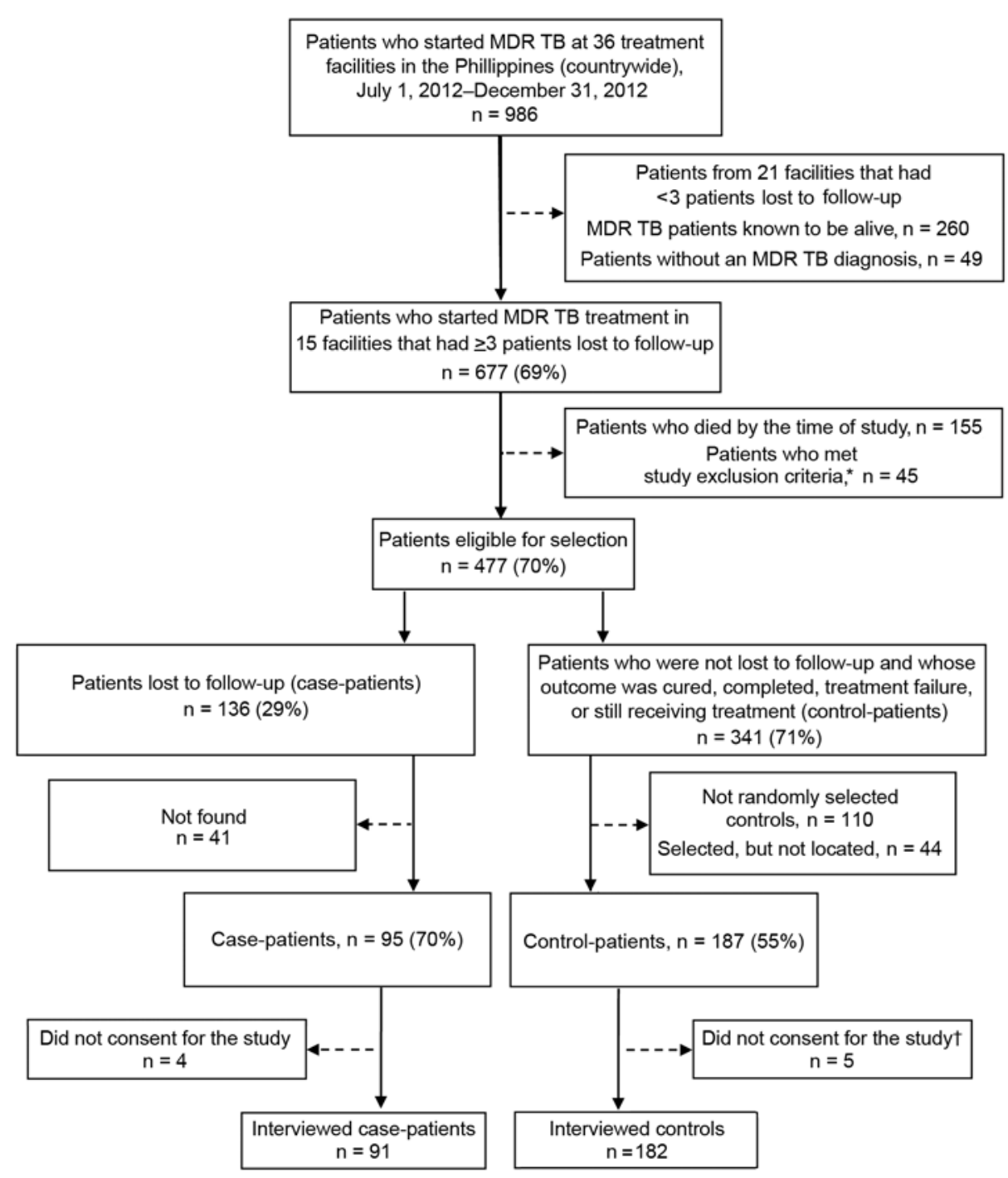

Figure 1. Selection of participants for study of loss to follow-up during treatment for multidrug resistant tuberculosis (MDR TB) in the Philippines, 2012-2014. *Study exclusion criteria were incarceration, age $<18$ years, enrollment in pharmaceutical clinical trials, and major psychiatric disorder or physical incapacitation. †Control-patients who did not give consent for the study were replaced by other randomly selected eligible patients. 
years; $164(60.1 \%)$ were male. An HIV test result was recorded for $56(20.5 \%)$ of the 273 patients; $2(3.5 \%)$ were HIV positive. All patients had pulmonary TB, and $35 \%$ had cavitary TB.

Most (70 [77.8\%]) of the 90 case-patients for whom information on length of treatment was available were lost to follow-up during the intensive phase of treatment. Mean \pm SD time receiving MDR TB treatment for case-patients was $7.8 \pm 3.4$ months (median 7 months; 25 th percentile 4 months; 75th percentile 11 months) and for control-patients was $19.8 \pm 1.7$ months (median 20 months; 25 th percentile 19 months; 75th percentile 21 months). Most (121 [66.5\%]) of the 182 control-patients were still receiving treatment at the time of interview. Among 61 control-patients for whom treatment outcome was available, 35 (57.4\%) experienced cure, $24(39.3 \%)$ completed treatment, and 2 (3.3\%) experienced treatment failure.

Univariate analysis indicated that individual factors significantly associated with loss to follow-up included older age (mean \pm SD age $42 \pm 13$ years for case-patients vs. $38 \pm 12$ years for control-patients; $p=0.028)$; tobacco smoking (odds ratio [OR] 2.86, 95\% CI 1.65-4.97); alcohol abuse (OR 1.93, 95\% CI 1.09-3.40); and residence in an urban slum (OR 0.52, 95\% CI 0.29-0.91) (Table 2). General knowledge of TB was significantly lower among case-patients than among control-patients; knowledge included understanding of the severity of and susceptibility to the disease (mean \pm SD score $67.8 \pm 16.3$ vs. $74.3 \pm$ 13.8 , respectively; $\mathrm{p}<0.001$ ), but recall for self-confidence for adhering to treatment at the time of treatment start was significantly higher among case-patients $(4.9 \pm 5.3$ vs. 2.44 \pm 3.8 , respectively, $\mathrm{p}<0.001)(20)$.

Univariate analysis also indicated that the only interpersonal factor significantly associated with loss to followup was social support from family and friends. Scores were lower among case-patients than among control-patients (mean \pm SD score $12.1 \pm 3.4$ vs. $12.9 \pm 3.0$, respectively, $\mathrm{p}$ $=0.047)$ (Table 3$)$.

Among healthcare setting factors, case-patients reported having received any type of assistance from the TB program significantly less often than control-patients: overall (OR 0.11, 95\% CI 0.04-0.29), food (OR 0.46, 95\% CI 0.27-0.79), free medications for treatment of adverse drug reactions (OR $0.28,95 \%$ CI $0.16-0.48$ ), or money for transportation (OR 0.19, 95\% CI 0.1-0.37) (Table 4). Scores for trust in, rapport with, and support from physicians and nursing staff were significantly lower among case-patients than among control-patients (mean $\pm \mathrm{SD}$ score $81.9 \pm 15.6$ vs. $90.7 \pm 7.8$, respectively; $\mathrm{p}<0.001$ ), as were scores for trust in and rapport with physicians $(56.0 \pm 11.5$ vs. $62.2 \pm 5.4$, respectively; $\mathrm{p}<0.001)$, trust in and rapport with nurses $(21.8 \pm 3.7$ vs. $23.8 \pm 2.4$, respectively; $\mathrm{p}<0.001$ ), and information and support received

\begin{tabular}{|c|c|c|}
\hline Social factors & \multicolumn{2}{|c|}{ - Policies and laws regulating healthcare access and delivery of care } \\
\hline $\begin{array}{l}\text { Diagnosis } \\
\text { and treatment }\end{array}$ & $\begin{array}{l}\text { - Out of pocket expenses } \\
\text { - Adverse events } \\
\text { - Treatment regimen } \\
\text { - Location: laboratory and radiograph }\end{array}$ & $\begin{array}{l}\text { - Disease severity } \\
\text { - DOTS services } \\
\text { - Clinical outcomes } \\
\text { hic services }\end{array}$ \\
\hline $\begin{array}{l}\text { Healthcare } \\
\text { setting factors }\end{array}$ & $\begin{array}{l}\text { - Perceptions of providers } \\
\text { - Patients perceptions of setting } \\
\text { - Patient-centered services }\end{array}$ & $\begin{array}{l}\text { - Patient enablers/incentives } \\
\text { - Policies/procedures }\end{array}$ \\
\hline Interpersonal factors & $\begin{array}{l}\text { - Family dynamics } \\
\text { - Peer influence }\end{array}$ & $\begin{array}{l}\text { ehold role } \\
\text { ar and family relationships }\end{array}$ \\
\hline Individual factors & $\begin{array}{lr}\text { - Demographics } & \text { Medic } \\
\text { - Knowledge, attitudes, beliefs, pe } \\
\text { - Social history } & \text { - Psycho }\end{array}$ & $\begin{array}{l}\text { al history } \\
\text { erceptions, and practices } \\
\text { ological factors }\end{array}$ \\
\hline
\end{tabular}

Figure 2. Social ecologic model used to identify factors influencing loss to follow-up during treatment for multidrug resistant tuberculosis in the Philippines, 2012-2014. Boldface indicates data collected through patient interviews and medical record abstractions. DOTS, directly observed therapy.

from healthcare center staff $(7.5 \pm 1.7$ vs. $8.4 \pm 1.2$, respectively; $\mathrm{p}<0.001$ ).

Among diagnosis and treatment factors, frequency of certain adverse drug reactions reported by patients did not differ significantly, except for less frequently reported diarrhea among case-patients (OR 0.49, 95\% CI 0.29-0.85). However, scores for self-reported severity of adverse drug reactions were significantly higher among case-patients; reactions included vomiting (mean \pm SD $5.23 \pm 3.72$ vs. $4.02 \pm 3.46 ; \mathrm{p}=0.008)$, dizziness $(5.48 \pm 3.51$ vs. $4.55 \pm$ $3.14 ; \mathrm{p}=0.029)$, and fatigue or extreme tiredness $(5.18 \pm$ 3.56 vs. $4.14 \pm 3.25 ; p=0.017$ ) (Tables 5, 6). Reported cost of travel to the treatment center during the intensive phase of treatment was significantly higher among case-patients than among control-patients (mean \pm SD $98 \pm 104$ pesos vs. $71 \pm 57$ pesos, respectively, $\mathrm{p}=0.035$ ).

Univariate analysis indicated that social factors significantly associated with loss to follow-up were selfreported lack of time to go to the treatment facility (OR $2.23,95 \%$ CI 1.1-4.54) and absence of someone to accompany the patient to the treatment facility during the intensive phase of treatment (OR 1.97, 95\% CI 1.06-3.65). Scores reflecting patient self-stigmatization among casepatients and control-patients did not differ significantly ( $p$ $=0.10)$ (Table 7).

Independent factors positively associated with loss to follow-up were alcohol abuse (OR 2.84, 95\% CI 1.395.80) and patient higher self-rating of vomiting severity (OR $1.10,95 \%$ CI $1.01-1.21$, per 1 point in severity rating score). Factors protective against loss to follow-up were receipt of any type of assistance from the TB program (OR $0.09,95 \%$ CI $0.03-0.25$ ); better general TB knowledge (OR $0.97,95 \%$ CI $0.95-0.99$, per 1 point in cumulative score); and higher levels of trust in, rapport with, and support from physicians and nursing staff (OR $0.93,95 \%$ CI 0.90-0.96, per 1 point in cumulative score) (Table 8). 
Table 1. Calculation of summary scores in study of loss to follow-up during treatment for multidrug-resistant TB, the Philippines, 2012-2014*

Score type

Score calculation

General TB knowledge, Participants were asked 15 questions that focused on

including understanding 1) the severity of the TB problem in their community,

of severity of the

disease and

susceptibility to the

disease

2) TB transmission and morbidity/mortality, and 3) TB treatment. Each item answered correctly was awarded 1 point. Incorrect answers or "Not sure" responses received 0 points. The summary score was extrapolated onto a scale of 100 and reported as a percentage by using the following formula: General TB knowledge score $=($ total points earned $/ 15) \times 100$ (i.e., score is calculated on a scale of $0-100 \%$ ).

Expectations related to Participants were asked 5 interview questions aimed TB and its treatment at determining their concerns for passing TB to loved ones, relapsing, and developing worsening drug resistance. Possible range of scores 5-15.
Score interpretation

A higher score may indicate greater TB knowledge and greater perceived severity and susceptibility to the disease.

A higher score may indicate greater concerns or an expectation that TB could cause problems in the future. In addition to factors such as knowledge, attitudes, and beliefs, expected outcomes can determine a person's actions. These expectations may be derived from 1) previous experiences, 2) observing or hearing about others in similar situations, 3) persuasive conversations, or 4) emotional or physical responses.

Self-efficacy (or Eight interview questions were included in the selfconfidence) to adhere to efficacy questionnaire. "Very confident" $=3$ points, "A treatment at the time treatment was about to begin

little confident" $=2$ points, "unsure" = 1 point, and "I knew I could not do this" $=0$ points. The score for each item would be added together to calculate a cumulative self-efficacy score. Possible range of scores $0-24$ points.

Social support from Score was based on responses to 3 interview
family and friends questions with possible range of scores 3-15.

Trust in, rapport with, An overall score was based on 22 items grouped and support from physicians and nursing staff together. Possible range of scores 22-110.
A higher score may indicate a high degree of selfreported self-efficacy for adhering to treatment regimen, coping with the treatment, and meeting with DOT staff when about to start treatment. Lower scores may indicate less support.

Patient selfA cumulative score for stigma was based on 2 stigmatization interview questions. Possible range of scores 1-10.

A higher score may indicate a greater level of trust, rapport, and perceived support. Items were separated by topic, and separate scores were also calculated for participants' 1) trust in, and rapport with physicians (13 questions); 2 ) trust in, and rapport with nurses (5 questions); and 3 ) perceived support from health center staff (4 questions). A higher score may indicate less stigma. ${ }^{*}$ DOTS, directly observed therapy; TB, tuberculosis.

The primary reason for stopping treatment, most commonly reported by case-patients, was medication side effects or the fear of side effects, reported by 52 (58\%) of 89 case-patients who responded to this question. The 2 other most commonly self-reported reasons for loss to follow-up were need to work and financial problems, reported by $25(28 \%)$ of 89 patients, and lack of money for transportation to the treatment facility, reported by 18 $(20 \%)$ of 89 patients.

\section{Discussion}

This large study, guided by a 5-level theoretical social ecologic model, demonstrated that loss to follow-up from MDR TB treatment in the Philippines was independently associated with 2 individual factors (general TB knowledge and alcohol abuse), 2 healthcare setting factors (receiving any type of assistance from the TB program and levels of trust in, rapport with, and support from physicians, nursing staff and other healthcare workers in the treatment facilities), and 1 diagnosis and treatment factor (higher self-rated severity of vomiting as an adverse drug reaction). Multivariable analysis did not identify any interpersonal or social factors associated with loss to follow-up. The most commonly reported primary reason for loss to follow-up was medication side effects or fear of side effects.

This study demonstrated that general TB knowledge was significantly lower among case-patients than among control-patients. Although nonadherence to treatment rarely results from patient apathy, patients' lack of knowledge of their medical condition and its treatment is associated with poor health outcomes (23). For this reason, patient education is a valuable component of TB control. A recent systematic review and meta-analysis demonstrated that provision of patient education was a strategy associated with lower rates of loss to follow-up (24). Among TB patients, interventions to improve general TB knowledge are significantly associated with better outcomes (25). Knowledge of the bacterial causation of TB, mode of transmission, diagnostic testing, meaning of test results, 
Table 2. Univariate analysis of Individual factors associated with loss to follow-up during treatment for multidrug-resistant TB, the Philippines, 2012-2014*

\begin{tabular}{|c|c|c|c|c|c|}
\hline Factor & Total† & Case-patients $\ddagger$ & Control-patients $\ddagger$ & Odds ratio $(95 \% \mathrm{Cl})$ & $p$ value \\
\hline \multicolumn{6}{|l|}{ Data from review of medical records } \\
\hline \multicolumn{6}{|l|}{ Demographics } \\
\hline \multicolumn{6}{|l|}{ Sex } \\
\hline M & 164 & $60(65.9)$ & $104(57.1)$ & $1.45(0.86-2.45)$ & 0.16 \\
\hline $\mathrm{F}$ & 109 & $31(34.1)$ & $78(42.9)$ & 1.00 & \\
\hline Age & 273 & $41.6(13.2) \S$ & $38.0(12.5) \S$ & $1.02(1.00-1.04) \pi$ & 0.028 \\
\hline \multicolumn{6}{|l|}{ Social history } \\
\hline \multicolumn{6}{|l|}{ Tobacco smoking } \\
\hline Current, past & 153 & $65(73)$ & $88(48.6)$ & $2.86(1.65-4.97)$ & $<0.001$ \\
\hline Never & 117 & $24(27)$ & $93(51.4)$ & 1.00 & \\
\hline \multicolumn{6}{|l|}{ Alcohol abuse } \\
\hline Current, past & 175 & $66(75)$ & 109 (60.9) & $1.93(1.09-3.4)$ & 0.02 \\
\hline Never & 92 & $22(25)$ & $70(39.1)$ & 1.00 & \\
\hline \multicolumn{6}{|l|}{ Drug abuse } \\
\hline Current, past & 52 & $19(22.4)$ & $33(18.6)$ & $1.26(0.67-2.37)$ & 0.48 \\
\hline Never & 210 & $66(77.6)$ & $144(81.4)$ & 1.00 & \\
\hline \multicolumn{6}{|l|}{ Clinical information } \\
\hline \multicolumn{5}{|l|}{$\mathrm{BMI}$} & 0.449 \\
\hline$<18.5$ & 146 & $51(56)$ & $95(52.2)$ & $1.17(0.7-1.94)$ & 0.55 \\
\hline$\geq 18.5$ & 127 & $40(44)$ & $87(47.8)$ & 1.00 & \\
\hline \multicolumn{6}{|l|}{ Cavitary TB disease } \\
\hline Yes & 97 & $31(44.3)$ & $66(41)$ & $1.14(0.65-2.02)$ & 0.64 \\
\hline No & 134 & $39(55.7)$ & $95(59)$ & 1.00 & \\
\hline \multicolumn{6}{|l|}{ Smear-positive at treatment start } \\
\hline Yes & 219 & $70(82.4)$ & $149(85.1)$ & $0.81(0.41-1.63)$ & 0.56 \\
\hline No & 41 & $15(17.6)$ & $26(14.9)$ & 1.00 & \\
\hline \multicolumn{6}{|l|}{ Data from patient interviews } \\
\hline $\begin{array}{l}\text { Total no. persons residing in household } \\
\text { Residence, comparison } 1\end{array}$ & 272 & $5.12(2.79) \S$ & $5.53(2.95) \S$ & $1.94(0.63-5.99) \pi$ & 0.27 \\
\hline Rural area & 40 & $15(23.4)$ & $25(24.5)$ & $0.94(0.45-1.96)$ & 0.88 \\
\hline Urban slum & 126 & 49 (76.6) & 77 (75.5) & 1.00 & \\
\hline \multicolumn{6}{|l|}{ Residence, comparison 2} \\
\hline Urban area & 105 & $26(34.7)$ & $79(50.6)$ & $0.52(0.29-0.91)$ & 0.02 \\
\hline Urban slum & 126 & $49(65.3)$ & $77(49.4)$ & 1.00 & \\
\hline \multicolumn{6}{|l|}{ Paid employment before starting treatment } \\
\hline Yes & 126 & $49(54.4)$ & $77(42.3)$ & $1.63(0.98-2.71)$ & 0.06 \\
\hline No & 146 & $41(45.6)$ & $105(57.7)$ & 1.00 & \\
\hline \multicolumn{6}{|c|}{ Employed before starting treatment but had to quit\# } \\
\hline Yes & 90 & $35(79.5)$ & $55(83.3)$ & $0.78(0.29-2.07)$ & 0.61 \\
\hline No & 20 & $9(20.5)$ & $11(16.7)$ & 1.00 & \\
\hline \multicolumn{6}{|c|}{ Employed before starting treatment but fired/asked to take leave of absence\# } \\
\hline Yes & 10 & $5(35.7)$ & $5(31.3)$ & $1.22(0.27-5.59)$ & $0.80^{* *}$ \\
\hline No & 20 & $9(64.3)$ & $11(68.8)$ & 1.00 & \\
\hline \multicolumn{6}{|c|}{ Family sold belongings or household items (assets) to help pay expenses during TB treatment } \\
\hline Yes & 93 & $28(31.8)$ & $65(35.7)$ & $0.84(0.49-1.44)$ & 0.53 \\
\hline No & 177 & $60(68.2)$ & $117(64.3)$ & 1.00 & \\
\hline \multicolumn{6}{|c|}{ Family borrowed money to cover costs due to TB illness } \\
\hline Yes & 181 & $60(74.1)$ & $121(70.8)$ & $1.18(0.65-2.14)$ & 0.58 \\
\hline No & 71 & $21(25.9)$ & $50(29.2)$ & 1.00 & \\
\hline General TB knowledge†† & 272 & $67.81(16.31) \S$ & $74.25(13.78) \S$ & $0.97(0.95-0.99) \pi$ & $<0.001$ \\
\hline $\begin{array}{l}\text { Expectations related to TB and TB } \\
\text { treatment }\end{array}$ & 272 & $11.01(1.87) \S$ & $10.76(1.55) \S$ & $1.10(0.94-1.28) \pi$ & 0.28 \\
\hline $\begin{array}{l}\text { Self-efficacy (or confidence) to adhere } \\
\text { to treatment at the time treatment was } \\
\text { about to begin }\end{array}$ & 272 & $4.91(5.28) \S$ & $2.44(3.77) \S$ & $1.13(1.06-1.19) \rrbracket$ & $<0.001$ \\
\hline $\begin{array}{l}\text { *Boldface indicates significance. BMI, body mass } \\
\text { †Total reflects number of patients for whom data o } \\
\text { †No. }(\%) \text { unless noted otherwise. } \\
\text { §Mean (SD). } \\
\text { TOdds ratio is per } 1 \text { unit increase. } \\
\text { \#Of } 126 \text { patients who had paid employment before } \\
\text { subsequently been "fired/asked to take leave of ab } \\
{ }^{* *} \text { Fisher exact test. }\end{array}$ & g treatn & 90 reported that th & $\begin{array}{l}\text { ere available. } \\
\text { dbsequently "had }\end{array}$ & nd 10 reported tha & \\
\hline
\end{tabular}


Table 3. Univariate analysis of interpersonal factors associated with loss to follow-up during treatment for multidrug-resistant TB, the Philippines, 2012-2014*

\begin{tabular}{|c|c|c|c|c|c|}
\hline Characteristic, from data from patient interviews & Total & Case-patients $\dagger$ & Control-patients $\dagger$ & Odds ratio $(95 \% \mathrm{Cl})$ & $p$ value \\
\hline \multicolumn{6}{|l|}{ Head of household $\ddagger$} \\
\hline Yes & 91 & $37(41.1)$ & $54(29.7)$ & $1.65(0.98-2.8)$ & 0.06 \\
\hline No & 181 & $53(58.9)$ & $128(70.3)$ & 1.00 & \\
\hline \multicolumn{6}{|l|}{ In charge of household budget } \\
\hline Yes & 96 & $32(35.6)$ & $64(35.2)$ & $1.02(0.6-1.72)$ & 0.95 \\
\hline No & 176 & $58(64.4)$ & $118(64.8)$ & 1.00 & \\
\hline Social support from family and friends & 271 & $12.07(3.35) \S$ & $12.87(2.99) \S$ & $0.92(0.85-1.00) \pi$ & 0.047 \\
\hline $\begin{array}{l}\text { *Boldface indicates significance. TB, tuberculosis. } \\
\text { †No (\%) unless noted otherwise. } \\
\text { †Provided more than half the cost of keeping up a hom } \\
\text { §Mean (SD). } \\
\text { ๆOdds ratio is per } 1 \text { unit increase. }\end{array}$ & $a$ & roming sick & & & \\
\hline
\end{tabular}

rationale for prolonged treatment, and effect of treatment interruptions should be clearly explained to patients and their loved ones. It is also crucial to educate patients about expected adverse events before starting treatment. Patient education that addresses commonly held misperceptions about TB may also discourage patients from consulting traditional healers, thereby avoiding delayed diagnosis and treatment (26).

Alcohol abuse was recorded in medical records at a significantly higher frequency for case-patients than for control-patients. The association between alcohol abuse or alcohol use disorders and loss to follow-up during MDR TB treatment has been demonstrated in multiple studies (13-15,27); 1 small randomized clinical trial demonstrated improved TB outcomes for patients in groups randomly assigned to receive naltrexone or behavioral counseling integrated into TB care (28). This finding, when combined with similar findings in other studies, calls for additional studies to assess the effect of using standard assessment tools to screen for alcohol dependence and of managing alcohol use as part of TB clinical services.

Receiving assistance from the TB program, including such measures as covering the cost of transportation, food, and housing, was associated with improved treatment adherence. However, if the process of applying for financial assistance is long and difficult and if this assistance is not given in a timely manner or regularly, patients may abandon their efforts to adhere to treatment. Decentralization of treatment (i.e., the transfer of care from a centralized MDR TB treatment center to a community DOTS facility) was protective; odds of being lost to follow-up decreased by 10 times (12). This finding suggests that the decentralization of care into multiple treatment facilities closer to patients' homes, which was used as part of the PMDT scale-up scheme in the Philippines, is a valid strategy for improving TB treatment patient retention. In addition to decentralization, the National TB Control Program began piloting the

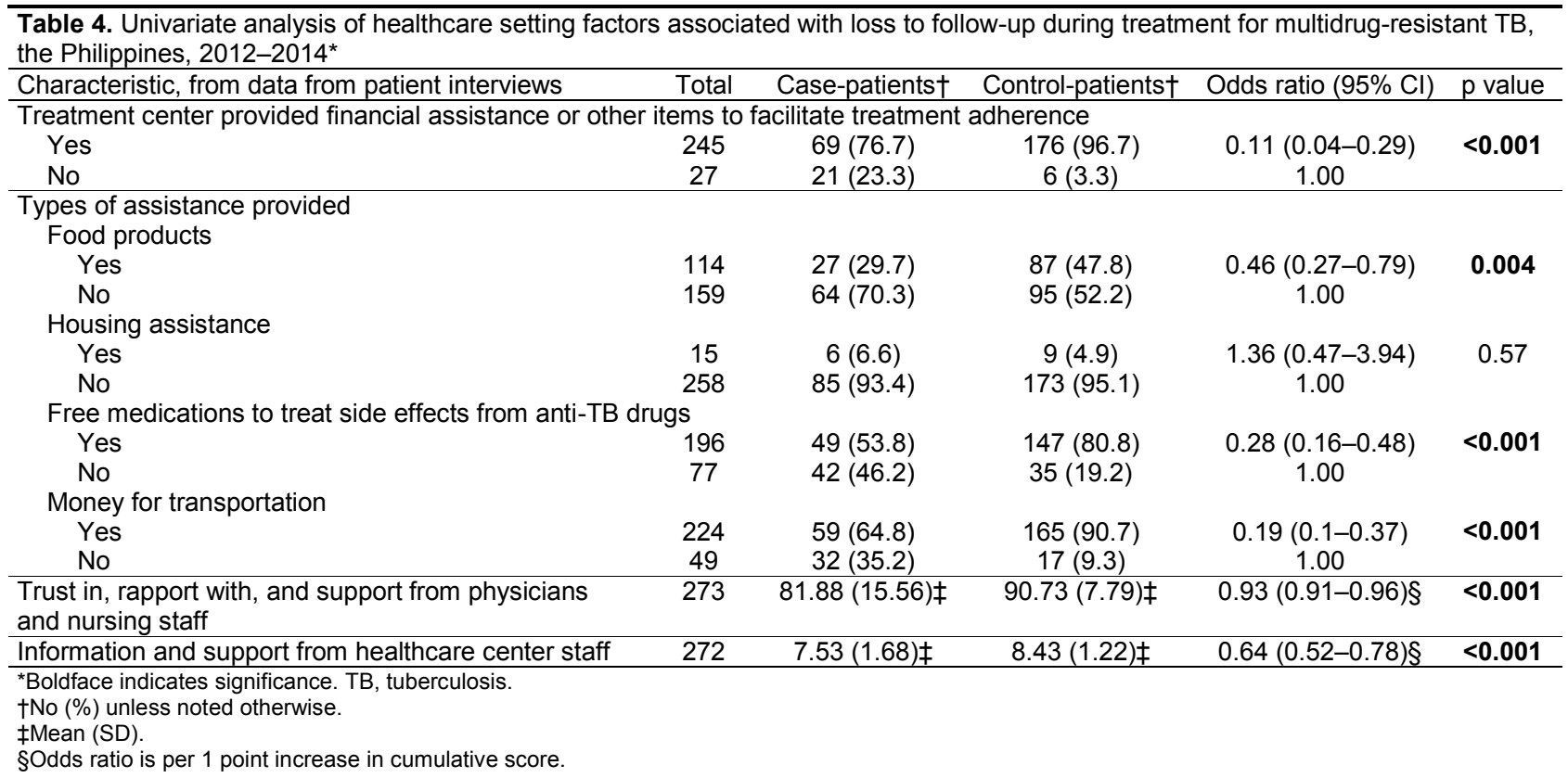


Community-Based PMDT Care Initiative in 2014 to provide a more accessible venue for management of MDR TB in the patient's home. The effectiveness of this initiative in improving treatment adherence should be rapidly evaluated, and the evaluation results should be used for future program planning. All modalities for addressing patient barriers should be considered. Adherence to MDR TB treatment might be improved by providing sufficient and timely financial assistance to patients (especially for transportation) by augmenting current enablers and providing livelihood programs during and after MDR TB treatment through strategic multisectoral partnership.

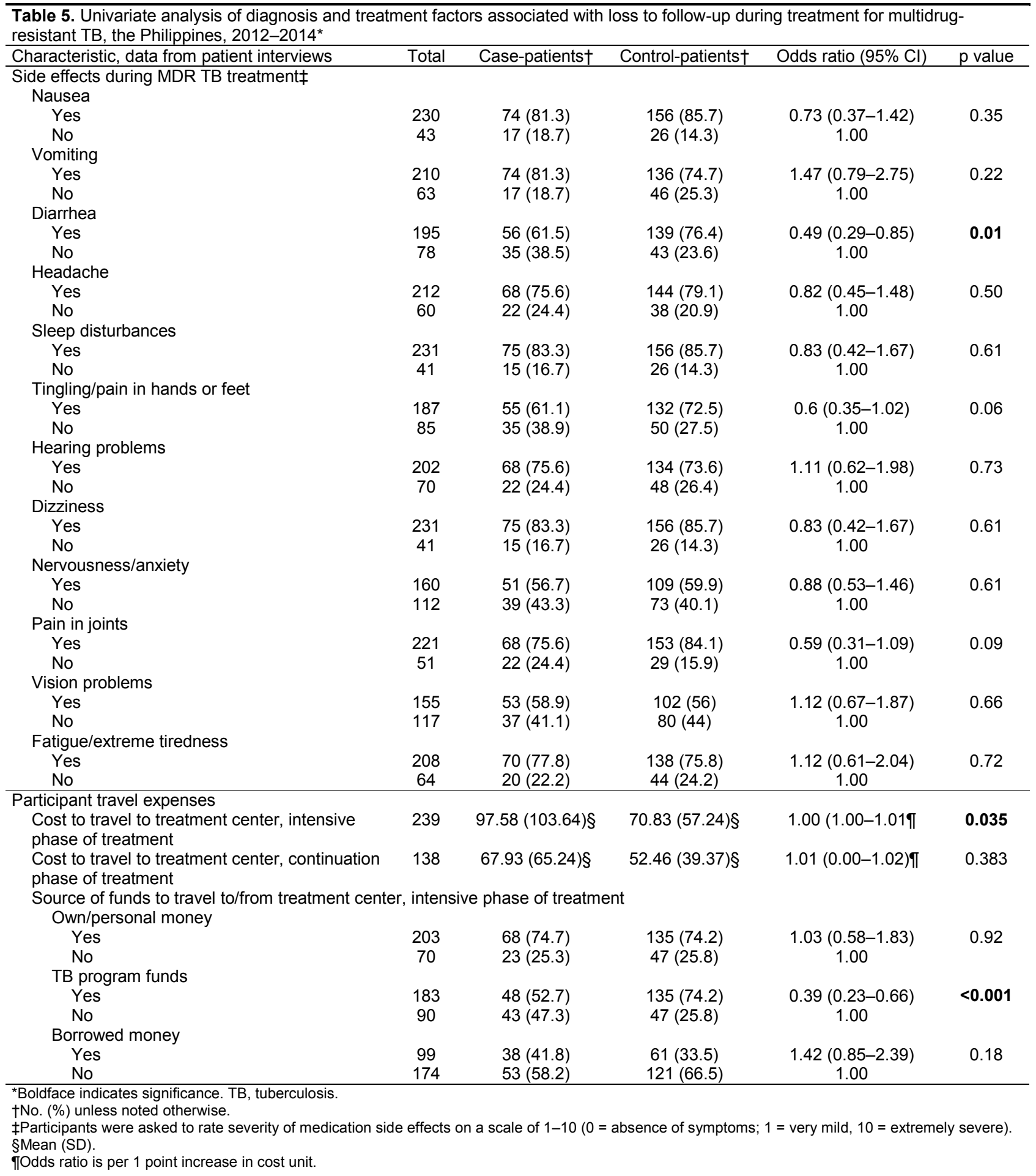


Loss to Follow-up during Treatment for MDR TB

Table 6. Rating of the severity of medication side effects experienced during treatment for multidrug-resistant TB, the Philippines, 2012-2014*

\begin{tabular}{|c|c|c|c|c|c|}
\hline Side effect & Total & $\begin{array}{l}\text { Case-patients, } \\
\text { mean (SD) score }\end{array}$ & $\begin{array}{l}\text { Control-patients, } \\
\text { mean (SD) score }\end{array}$ & Odds ratio $(95 \% \mathrm{Cl}) \dagger$ & $p$ value \\
\hline Nausea & 273 & $5.05(3.51)$ & $4.42(3.18)$ & $1.06(0.98-1.14)$ & 0.136 \\
\hline Vomiting & 273 & $5.23(3.72)$ & $4.02(3.46)$ & $1.10(1.02-1.18)$ & 0.008 \\
\hline Diarrhea & 273 & $3.34(3.41)$ & $3.74(3.18)$ & $0.96(0.89-1.04)$ & 0.345 \\
\hline Headache & 272 & $4.37(3.36)$ & $4.20(3.23)$ & $1.02(0.94-1.10)$ & 0.689 \\
\hline Sleep disturbances & 272 & $5.23(3.59)$ & $5.31(3.26)$ & 0.99 (0.92-1.07) & 0.854 \\
\hline Tingling/pain in hands or feet & 272 & $3.58(3.53)$ & $4.14(3.56)$ & $0.96(0.89-1.03)$ & 0.218 \\
\hline Hearing problems & 272 & $4.49(3.47)$ & $4.13(3.46)$ & $1.03(0.96-1.11)$ & 0.417 \\
\hline Dizziness & 272 & $5.48(3.51)$ & $4.55(3.14)$ & $1.09(1.01-1.18)$ & 0.029 \\
\hline Nervousness/anxiety & 272 & $3.26(3.34)$ & $3.01(3.16)$ & $1.02(0.95-1.11)$ & 0.548 \\
\hline Skin problems or rash & 272 & $2.70(3.26)$ & $2.69(3.22)$ & $1.00(0.93-1.08)$ & 0.975 \\
\hline Joint pain & 272 & $5.14(3.57)$ & $5.49(3.34)$ & $0.97(0.90-1.04)$ & 0.427 \\
\hline Vision problems & 272 & $3.10(3.07)$ & $2.80(3.05)$ & $1.03(0.95-1.12)$ & 0.45 \\
\hline Fatigue/extreme tiredness & 272 & $5.18(3.56)$ & $4.14(3.25)$ & $1.10(1.02-1.18)$ & 0.017 \\
\hline
\end{tabular}

We found that levels of trust in, rapport with, and support from physicians, nursing staff, and other caregivers in the treatment facilities were significantly lower among patients lost to follow-up than among controlpatients. A higher degree of trust, good rapport, and support from providers has been shown to be associated with patients' adherence to medical recommendations and with improvements to self-reported and objective measures of health (29-31). In a study by Holtz et al. in South Africa, the strongest individual risk factor for nonadherence to MDR TB treatment was having an unsatisfactory opinion about the attitude of the healthcare workers (32). Interventions focused on enhancing provider-patient mutual trust and respect are needed. Provider training with regard to active listening, health literacy, message-framing, motivational interviewing, communication skills for trust-building and sensitivity should be considered.

We found that patients' higher rating of the severity of their vomiting was independently associated with loss to follow-up. Moreover, the most commonly reported reason for stopping treatment $(58 \%)$ was medication side effects. However, frequency of adverse drug reactions reported by patients in interviews did not differ significantly between case-patients and control-patients (except that diarrhea symptoms were reported significantly less often by case-patients than by control-patients). Still, case-patients reported significantly higher subjectively perceived severity of vomiting, dizziness, and fatigue as medication side effects. These symptoms affect quality of life and interfere with the capacity to work and the ability to engage in activities of daily living. A study of 583 MDR TB patients in the Philippines who had undergone treatment during 1999-2006 showed that taking >5 drugs was significantly associated with loss to follow-up compared with taking 2-3 drugs (12). The authors interpreted the association between a higher drug burden and loss to follow-up as being related to more extensive drug resistance and competing risk for death among those patients. However, it also might be related to experiencing more side effects by the patients who received a higher number of toxic second-line drugs, which more likely led to stopping treatment, than by patients who received a lower number of drugs. Our study suggests that strict monitoring for, and appropriate treatment of, adverse drug reactions may help improve treatment adherence. Ancillary drugs must be included in procurement plans and made widely available at treatment facilities. Initial and refresher trainings for healthcare providers about management of adverse drug reactions and patient education about expected adverse drug reactions before treatment initiation may also help improve treatment adherence. Patients should understand the need for strict monitoring for adverse drug reactions and the availability of effective and free treatment for those reactions, especially reactions that are subjectively difficult for patients (e.g., nausea, vomiting, dizziness, and extreme fatigue).

Our study is subject to several limitations. As with any case-control study, it provides relatively weak empirical evidence. Because patient interviews were part of the protocol, deceased patients were excluded, which might have introduced survivor biases into our results. Almost a third of selected control-patients could not be located, which could bias the results in favor of selecting control-patients with a stronger relationship to the clinics. The retrospective nature of interviews is also subject to recall and exposure misclassification biases. Interview responses may reflect socially desirable answers rather than true thoughts and experiences. Some patients who were adherent to treatment at the time of the interview may be lost to follow-up at a later time (in this study, $66 \%$ of control-patients were still receiving treatment at the time of the interview); thus, outcome misclassification is possible. Identification of alcohol abuse was based on 
the records in medical charts without standardized assessment for each patient (such as the Alcohol Use Disorder Identification Test) (33). Previous studies have demonstrated that loss to follow-up from treatment was less in smaller cohorts (24) and was more with program scale-up (34). Thus, increased loss to follow-up may be related to healthcare setting structural factors such as insufficient number of facilities and providers or limited experience with management of MDR TB, but our study did not address those factors.
Despite these limitations, our study provides useful data. The interviews captured patients' perspectives and provided nuances that retrospective cohort studies lack $(11,12,15-17)$. These data, along with medical record data, afford program leaders greater insight for improving services and designing patient-centered interventions to reduce loss to followup during MDR TB treatment in the Philippines. A revision of the PMDT strategy should address identified barriers to completing MDR TB treatment and implement actions that support patients' adherence to treatment.

Table 7. Univariate analysis of social factors associated with loss to follow-up during treatment for multidrug-resistant TB, the Philippines, 2012-2014*

\begin{tabular}{|c|c|c|c|c|c|}
\hline Category & Total & Case-patients $\dagger$ & Control-patients $†$ & Odds ratio $(95 \% \mathrm{Cl})$ & $p$ value \\
\hline \multicolumn{6}{|c|}{$\begin{array}{l}\text { Distance between participant's home and treatment center, intensive phase of treatment } \\
\text { Comparison } 1\end{array}$} \\
\hline 0 to $<1 \mathrm{~km}$ & 23 & $7(23.3)$ & $16(31.4)$ & \multirow{2}{*}{$\begin{array}{l}0.67(0.24-1.87) \\
1.00\end{array}$} & \multirow[t]{2}{*}{0.44} \\
\hline 1 to $<5 \mathrm{~km}$ (referent) & 58 & $23(76.7)$ & $35(68.6)$ & & \\
\hline \multicolumn{6}{|l|}{ Comparison 2} \\
\hline 5 to $<10 \mathrm{~km}$ & 46 & $13(36.1)$ & $33(48.5)$ & \multirow{3}{*}{$\begin{array}{l}0.6(0.26-1.37) \\
1.00\end{array}$} & \multirow[t]{2}{*}{0.23} \\
\hline 1 to $<5 \mathrm{~km}$ (referent) & 58 & $23(63.9)$ & $35(51.5)$ & & \\
\hline \multicolumn{5}{|l|}{ Comparison 3} & \\
\hline$>10 \mathrm{~km}$ & 104 & $38(62.3)$ & $66(65.3)$ & \multirow{3}{*}{$\begin{array}{l}0.88(0.45-1.7) \\
1.00\end{array}$} & \multirow[t]{2}{*}{0.69} \\
\hline$\overline{1}$ to $<5 \mathrm{~km}$ (referent) & 58 & $23(37.7)$ & $35(34.7)$ & & \\
\hline \multicolumn{5}{|l|}{ Comparison 4} & \\
\hline Not sure/don't know & 42 & $10(30.3)$ & $32(47.8)$ & \multirow{2}{*}{$\begin{array}{l}0.48(0.2-1.15) \\
1.00\end{array}$} & \multirow[t]{2}{*}{0.10} \\
\hline 1 to $<5 \mathrm{~km}$ (referent) & 58 & $23(69.7)$ & $35(52.2)$ & & \\
\hline \multirow{2}{*}{\multicolumn{6}{|c|}{$\begin{array}{l}\text { Usual mode of transportation/transportation used to cover the greatest distance } \\
\text { traveling to the treatment center, intensive phase of treatment } \\
\text { Walk }\end{array}$}} \\
\hline & & & & & \\
\hline Yes & 37 & $19(20.9)$ & $18(9.9)$ & $2.4(1.19-4.85)$ & \multirow[t]{2}{*}{0.01} \\
\hline No & 236 & $72(79.1)$ & $164(90.1)$ & 1.00 & \\
\hline \multicolumn{6}{|l|}{ Public transportation } \\
\hline Yes & 239 & $79(86.8)$ & $160(87.9)$ & $0.91(0.43-1.92)$ & \multirow[t]{2}{*}{0.80} \\
\hline No & 34 & $12(13.2)$ & $22(12.1)$ & 1.00 & \\
\hline \multicolumn{6}{|l|}{ Personal vehicle } \\
\hline Yes & 16 & $6(6.6)$ & $10(5.5)$ & $1.21(0.43-3.45)$ & \multirow[t]{2}{*}{0.72} \\
\hline No & 257 & $85(93.4)$ & $172(94.5)$ & 1.00 & \\
\hline \multirow{2}{*}{\multicolumn{6}{|c|}{$\begin{array}{l}\text { Major challenges when traveling to the treatment center, intensive phase of treatment } \\
\text { The center was far away }\end{array}$}} \\
\hline & & & & & \\
\hline No & 141 & $\begin{array}{l}52(51.0) \\
38(422)\end{array}$ & $\begin{array}{l}89(48.9) \\
93(511)\end{array}$ & $1.43(0.86-2.38)$ & 0.17 \\
\hline \multicolumn{6}{|l|}{ Did not always have money for transportation } \\
\hline Yes & 193 & $71(78)$ & $122(67.4)$ & $1.72(0.96-3.08)$ & \multirow[t]{2}{*}{0.07} \\
\hline No & 79 & $20(22)$ & $59(32.6)$ & 1.00 & \\
\hline \multicolumn{6}{|l|}{ Did not have the time to go for treatment } \\
\hline Yes & 36 & $18(19.8)$ & $18(9.9)$ & $2.23(1.1-4.54)$ & \multirow[t]{2}{*}{0.02} \\
\hline No & 236 & $73(80.2)$ & $163(90.1)$ & 1.00 & \\
\hline Going for treatment caused problems with work & & & & & \\
\hline Yes & 81 & $33(36.3)$ & $48(26.5)$ & $1.58(0.92-2.71)$ & 0.10 \\
\hline No & 191 & $58(63.7)$ & $133(73.5)$ & 1.00 & \\
\hline Did not have anyone to go with & & & & & \\
\hline Yes & 52 & $24(26.4)$ & $28(15.4)$ & $1.97(1.06-3.65)$ & 0.03 \\
\hline No & 221 & $67(73.6)$ & $154(84.6)$ & 1.00 & \\
\hline The center's hours were not convenient & & & & & \\
\hline Yes & 23 & $11(12.1)$ & $12(6.6)$ & $1.95(0.82-4.6)$ & 0.12 \\
\hline No & 250 & 80 (87.9) & $170(93.4)$ & 1.00 & \\
\hline $\begin{array}{l}\text { Minutes to travel from home to treatment center, } \\
\text { intensive phase of treatment }\end{array}$ & 272 & $51.00(43.56) \ddagger$ & $54.16(45.03) \ddagger$ & $1.00(0.99-1.00) \S$ & 0.583 \\
\hline Minutes to travel from home to treatment center, & 198 & $22.25(15.93) \ddagger$ & $31.07(36.94) \ddagger$ & $0.99(0.97-1.01) \S$ & 0.057 \\
\hline Patient self-stigmatization & 272 & $6.20(2.76) \ddagger$ & $5.66(2.44) \ddagger$ & $1.09(0.98-1.20) \S$ & 0.104 \\
\hline
\end{tabular}


Table 8. Multivariable analysis of factors associated with loss to follow-up during treatment for multidrug-resistant TB, the Philippines, 2012-2014*

\begin{tabular}{lcc}
\hline Social ecologic model level, factor & Odds ratio (95\% Cl) & \\
\hline Personal factors & & \\
$\quad$ Score TB knowledge & $0.97(0.95-0.99) \dagger$ & \\
$\quad$ Alcohol abuse & $2.84(1.39-5.80)$ & 0.003 \\
\hline Healthcare setting factors & $0.09(0.03-0.25)$ & 0.004 \\
$\quad$ Received assistance from TB program & $0.93(0.90-0.96) \dagger$ & $<0.001$ \\
$\quad$ Score trust/rapport with healthcare worker & $1.10(1.01-1.21) \ddagger$ & $<0.001$ \\
\hline Diagnosis and treatment factors & & \\
$\quad$ Self-rated severity of vomiting as adverse drug reaction & & 0.03 \\
\hline
\end{tabular}

${ }^{*}$ TB, tuberculosis.

tOdds ratio is per 1 point increase in cumulative score.

¥Odds ratio is per 1 point increase in severity rating score.

\section{Acknowledgments}

We acknowledge the dedication and incredible work of John Paul Sazaila L. Aliazas, Jay-ar A. Ambunan, Marco B. Anonas, Mercy T. Baylon, Mikaela Angela A. Gabatin, Paula Danella S. Mallari, Freddy Evangelista Romano, and Mhon Adrian G. Pereña. We appreciate the support and assistance with the study design and manuscript review provided by Peter Cegielski, Amera R. Khan, and Wanda Walton. We thank the medical officers and staff of the treatment centers, satellite treatment centers, and health centers in the Philippines, who graciously assisted with this project. And we express our gratitude to the MDR TB patients who kindly agreed to participate in this study.

Funding for this study was provided by USAID Philippines through cooperative agreement with Philippine Business for Social Progress for the Innovations and Multisectoral Partnership to Achieve Control of Tuberculosis project.

Dr. Tupasi is a founding president of the Tropical Disease Foundation based in Metro Manila, the Philippines. Her interests include tuberculosis and other infectious diseases, along with establishment of the first Green Light Committee-approved Programmatic Management of Drug-Resistant Tuberculosis Program.

\section{References}

1. World Health Organization. Countdown to 2015: global tuberculosis report 2013 supplement [cited $2015 \mathrm{Jul} 24$ ]. http://apps.who.int/iris/bitstream/10665/91542/1/WHO_HTM_ TB_2013.13_eng.pdf

2. Ahuja SD, Ashkin D, Avendano M, Banerjee R, Bauer M, Bayona JN, et al. Multidrug resistant pulmonary tuberculosis treatment regimens and patient outcomes: an individual patient data meta-analysis of 9,153 patients. PLoS Med. 2012;9:e1001300. http://dx.doi.org/10.1371/ journal.pmed.1001300

3. Fitzpatrick C, Floyd K. A systematic review of the cost and cost effectiveness of treatment for multidrug-resistant tuberculosis. Pharmacoeconomics. 2012;30:63-80. http://dx.doi.org/10.2165/ 11595340-000000000-00000

4. Orenstein EW, Basu S, Shah NS, Andrews JR, Friedland GH, Moll AP, et al. Treatment outcomes among patients with multidrug-resistant tuberculosis: systematic review and meta-analysis. Lancet Infect Dis. 2009;9:153-61. http://dx.doi.org/ 10.1016/S1473-3099(09)70041-6
5. Ramachandran G, Swaminathan S. Safety and tolerability profile of second-line anti-tuberculosis medications. Drug Saf. 2015;38:25369. http://dx.doi.org/10.1007/s40264-015-0267-y

6. World Health Organization. Tuberculosis country profiles [cited $2015 \mathrm{Jul}$ 24]. https://extranet.who.int/sree/Reports?op=Replet \&name $=\% 2 \mathrm{FWHO}$ HQ_Reports $\% 2 \mathrm{FG} 2 \% 2 \mathrm{FPROD} \% 2 \mathrm{FEXT} \% 2 \mathrm{~F}$ TBCountryProfile \&ISO $2=$ PH\&LAN $=$ EN\&outtype $=$ pdf

7. Tupasi TE, Quelapio MID, Orillaza RB, Alcantara C, Mira NRC, Abeleda MR, et al. DOTS-Plus for multidrug-resistant tuberculosis in the Philippines: global assistance urgently needed. Tuberculosis (Edinb). 2003;83:52-8. http://dx.doi.org/10.1016/S1472-9792 (02)00072-0

8. The Philippines Department of Health. Report of accomplishments and targets of the Programmatic Management for Drug-resistant Tuberculosis program in the Philippines; 2014 [cited 2015 Jul 24]. http://www.doh.gov/ph/

9. Cegielski JP, Kurbatova E, van der Walt M, Brand J, Ershova J, Tupasi T, et al. Multidrug-resistant tuberculosis treatment outcomes in relation to treatment, initial and acquired secondline drug resistance. Clin Infect Dis. 2015. Oct 27. pii: civ910. Epub ahead of print [cited 2015 Jul 24]. http://www.ncbi.nlm.nih.gov/ pubmed/26508515

10. Kurbatova E, Caoili JC, Contreras C, Ershova J, Dalton T, Kvasnovsky C, et al. Loss to follow up from multidrug-resistant tuberculosis treatment and acquired drug resistance. Presented at: 45th Union World Conference on Lung Health 2014; 2014 Oct 28-Nov 1; Barcelona, Spain.

11. Gelmanova IY, Keshavjee S, Golubchikova VT, Berezina VI, Strelis AK, Yanova GV, et al. Barriers to successful tuberculosis treatment in Tomsk, Russian Federation: non-adherence, default and the acquisition of multidrug resistance. Bull World Health Organ. 2007;85:703-11. http://dx.doi.org/10.2471/ BLT.06.038331

12. Gler MT, Podewils LJ, Munez N, Galipot M, Quelapio MID, Tupasi TE. Impact of patient and program factors on default during treatment of multidrug-resistant tuberculosis. Int J Tuberc Lung Dis. 2012;16:955-60. http://dx.doi.org/10.5588/ ijtld. 11.0502

13. Jakubowiak WM, Bogorodskaya EM, Borisov SE, Danilova ID, Kourbatova EV. Risk factors associated with default among new pulmonary TB patients and social support in six Russian regions. Int J Tuberc Lung Dis. 2007;11:46-53.

14. Kendall EA, Theron D, Franke MF, van Helden P, Victor TC, Murray MB, et al. Alcohol, hospital discharge, and socioeconomic risk factors for default from multidrug resistant tuberculosis treatment in rural South Africa: a retrospective cohort study. PLoS ONE. 2013;8:e83480. http://dx.doi.org/10.1371/ journal.pone. 0083480

15. Kliiman K, Altraja A. Predictors and mortality associated with treatment default in pulmonary tuberculosis. Int J Tuberc Lung Dis. 2010;14:454-63. 
16. Kuchukhidze G, Kumar AMV, de Colombani P, Khogali M, Nanava U, Blumberg HM, et al. Risk factors associated with loss to follow-up among multidrug-resistant tuberculosis patients in Georgia. Public Health Action. 2014;4(Suppl 2):S41-6. http://dx.doi.org/10.5588/pha.14.0048

17. Shringarpure KS, Isaakidis P, Sagili K, Baxi RK. Loss-to-follow-up on multidrug resistant tuberculosis treatment in Gujarat, India: the when and who of it. PLoS ONE. 2015;10:e0132543. http://dx.doi.org/10.1371/journal.pone.0132543

18. World Health Organization (WHO). Definitions and reporting framework for tuberculosis-2013 revision [cited 2015 Jul 24]. http://apps.who.int/iris/bitstream/10665/79199/1/ 9789241505345_eng.pdf

19. Centers for Disease Control and Prevention. Colorectal Cancer Control Program. Social ecological model of health promotion [cited 2014 Jan 8]. http://www.cdc.gov/cancer/crccp/sem.htm

20. Golden SD, Earp JAL. Social ecological approaches to individuals and their contexts: twenty years of health education \& behavior health promotion interventions. Health Educ Behav. 2012;39:364 72. http://dx.doi.org/10.1177/1090198111418634

21. Bandura A. Self-efficacy: toward a unifying theory of behavioral change. Psychol Rev. 1977;84:191-215. http://dx.doi.org/10.1037/ 0033-295X.84.2.191

22. Kleinbaum DG, Klein M, Pryor ER. Logistic regression: a selflearning text. New York: Springer-Verlag; 2002. p. 161-226.

23. US Department of Health and Human Services. Quick guide to health literacy [cited 2015 Nov 20]. http://health.gov/ communication/literacy/quickguide/Quickguide.pdf

24. Toczek A, Cox H, du Cros P, Cooke G, Ford N. Strategies for reducing treatment default in drug-resistant tuberculosis: systematic review and meta-analysis. Int J Tuberc Lung Dis. 2013;17:299-307. http://dx.doi.org/10.5588/ijtld.12.0537

25. M'imunya JM, Kredo T, Volmink J. Patient education and counselling for promoting adherence to treatment for tuberculosis. Cochrane Database Syst Rev. 2012;5:CD006591.

26. Viney KA, Johnson P, Tagaro M, Fanai S, Linh NN, Kelly P, et al. Tuberculosis patients' knowledge and beliefs about tuberculosis: a mixed methods study from the Pacific Island nation of Vanuatu.
BMC Public Health. 2014;14:467. http://dx.doi.org/10.1186/ 1471-2458-14-467

27. Kurbatova EV, Taylor A, Gammino VM, Bayona J, Becerra M, Danilovitz M, et al. Predictors of poor outcomes among patients treated for multidrug-resistant tuberculosis at DOTS-Plus projects. Tuberculosis (Edinb). 2012;92:397-403. http://dx.doi.org/10.1016/j.tube.2012.06.003

28. Shin S, Livchits V, Connery H, Shields A, Yanov S, Yanova G, et al. Effectiveness of alcohol treatment interventions integrated into routine tuberculosis care in Tomsk, Russia. Addiction. 2013;108:1387-96. http://dx.doi.org/10.1111/add.12148

29. Dibben MR, Morris SE, Lean ME. Situational trust and co-operative partnerships between physicians and their patients: a theoretical explanation transferable from business practice. QJM. 2000;93:55-61. http://dx.doi.org/10.1093/ qjmed/93.1.55

30. Lee Y-Y, Lin JL. The effects of trust in physician on self-efficacy, adherence and diabetes outcomes. Soc Sci Med. 2009;68:1060-8. http://dx.doi.org/10.1016/j.socscimed.2008.12.033

31. Safran DG, Montgomery JE, Chang H, Murphy J, Rogers WH. Switching doctors: predictors of voluntary disenrollment from a primary physician's practice. J Fam Pract. 2001;50:130-6.

32. Holtz TH, Lancaster J, Laserson KF, Wells CD, Thorpe L, Weyer K. Risk factors associated with default from multidrugresistant tuberculosis treatment, South Africa, 1999-2001. Int J Tuberc Lung Dis. 2006;10:649-55.

33. World Health Organization. AUDIT, The Alcohol Use Disorders Identification Test: guidelines for use in primary care. 2nd ed. WHO/MSD/MSB/01.6a. Geneva: The Organization; 2001.

34. Lalor MK, Greig J, Allamuratova S, Althomsons S, Tigay Z, Khaemraev A, et al. Risk factors associated with default from multi- and extensively drug-resistant tuberculosis treatment, Uzbekistan: a retrospective cohort analysis. PLoS ONE. 2013;8:e78364. http://dx.doi.org/10.1371/journal.pone.0078364

Address for correspondence: Thelma E. Tupasi, Tropical Disease Foundation, Inc., Amorsolo St and Urban Ave, Barangay, Pio Del Pilar, Makati City 1230, the Philippines; email: tetupasi@yahoo.com

\section{Dr. Mike Miller reads an abridged version of the article Knemidocoptic Mange in Wild Golden Eagles, California, USA}
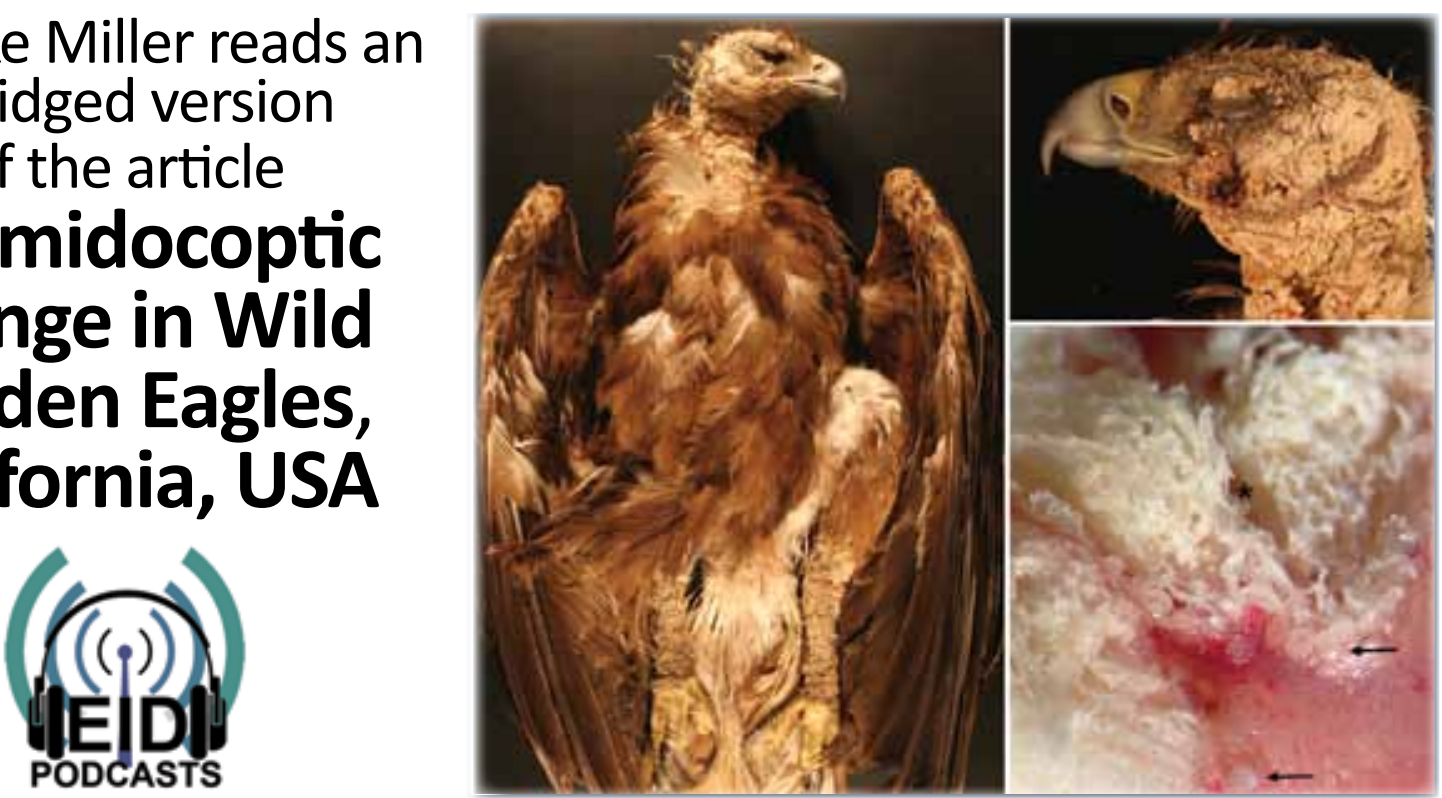

Download or listen here: http://www2c.cdc.gov/podcasts/player.asp?f=8634354 